\section{Edyrcasaice

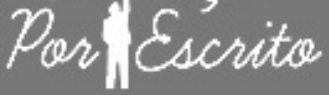

ARTIGO

\title{
Liderança multifacetada e em contracorrente à erosão da gestão democrática: a ação de um diretor de escola
}

\author{
Multifaceted leadership and in countercurrent to the erosion of \\ democratic management: the action of a school director
}

\section{Editor}

Alexandre Anselmo Guilherme PUCRS, RS, Brasil

\section{Editor Assistente}

\section{Cibele Cheron}

PUCRS, RS, Brasil

\section{Editores Associados}

Bruno Antonio Picoli

Universidade Federal da Fronteira Sul, Chapecó, SC, Brasil

Pricila Kohls dos Santos Universidade Católica de Brasília, Brasília, DF, Brasil

Renato de Oliveira Brito

Universidade Católica de Brasilia, Brasilia, DF, Brasil

Elisa Ustarroz

PUCRS, Porto Alegre, RS, Brasil

\section{ISSN 2179-8435}

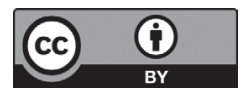

Este artigo está licenciado sob forma de uma licença Creative Commons Atribuição 4.0 Internacional, em qualquer meio, desde que a publicaçăo original se corretamente citada.

http://creativecommons.org/licenses/by/4.0/deed.pt_BR
Fernanda Martins $\oplus^{1}$

Ana Paula Macedo ${ }^{1}$

1 Universidade do Minho, Centro de Investigação em Educação, Portugal.

\section{RESUMO}

O presente estudo parte do princípio que o atual modelo de gestão, Decreto-Lei no 75/2008, de 22 de abril, ao atribuir centralidade ao diretor da escola não agrupada ou agrupamento de escolas pode ser um fator de erosão da gestão democrática e, consequentemente, de fragmentação das práticas de colegialidade dos profissionais. Para uma compreensão, no plano da ação, dessa nova realidade, recorreu-se ao método do estudo de caso e apresentam-se dados relacionados com o perfil do diretor da escola, bem como com a liderança exercida por esse ator no anterior e no atual modelo de gestão. Neste âmbito, as técnicas de recolha de dados consistiram no inquérito por entrevista a diferentes atores escolares, bem como na análise de documentos de cariz oficial. Os resultados deste estudo apontam para a existência de uma congregação de ações e lógicas afetas tanto a uma liderança de tipo empresarial e gerencial, como a uma liderança antagonista/reivindicativa e, ainda, a uma liderança democrática. É nesse contexto que são reveladas algumas dimensões dos diferentes tipos de liderança, uma liderança multifacetada, rompendo com um certo mito de um tipo único de liderança exercido pelo diretor de escola, independentemente dos grupos com quem interage, das situações imprevistas e das incertezas que venham a surgir no quotidiano de uma escola.

Palavras-chave: Novo modelo de gestão. Gestão democrática. Diretor de escola. Tipo de liderança.

\section{ABSTRACT}

The present study assumes that the current management model by assigning centrality to the director of the non-grouped school or grouping of schools can be a factor in the erosion of democratic management and, consequently, in the fragmentation of professional collegiality practices. For an understanding of this new reality a case study is carried out based on the available data, related with the profile of the director of the school, as 
well as the leadership exercised by this actor in the previous management models and current. In this context, we emphasize, as data collection techniques, the interview survey of different school actors, as well as the analysis of official documents. The results of this study point to the existence of a congregation of actions and logics related to both empresarial leadership, as well as antagonistic/confrontation leadership, insofar as the director seeks to have the voice of the ministry of education decisions affecting the school.It is in this context that some dimensions of the different types of leadership are revealed, a multifaceted leadership, breaking with a certain myth of a unique type of leadership, regardless of the groups that interact, the unforeseen situations and the uncertainties in the daily life of a school.

Keywords: New management model. Democratic management. School principal. Type of leadership.

\section{Introdução}

A gestão democrática das escolas em Portugal, que emerge com a Revolução dos Cravos, encontra-se associada, entre outros aspetos, à democraticidade e eleição, à colegialidade e à participação (LIMA, 2014). Assim, durante mais de 30 anos (até 2008), assistiu-se à eleição dos membros de órgãos diretivos colegiais das escolas públicas ${ }^{1}$, em contraste com o regime de nomeação anterior, classificado por autoritário.

Para além deste caráter democrático de que se reveste a eleição do conselho diretivo e, mais tarde, do conselho executivo, também destacamos a existência de outros órgãos colegiais, com representantes eleitos e com capacidade de eleição do seu presidente, quer no caso de outro órgão de gestão de topo, entretanto criado (em 1998 com a designação de assembleia de escola e em 2008 de o conselho geral), quer de alguns órgãos de gestão pedagógica intermédia (LIMA, 2014). De modo específico, reforçamos que no caso dos órgãos de gestão intermédia parece fundamental ter em linha de conta que estes detinham a possibilidade de escolha democrática dos seus líderes, nomeadamente do presidente do conselho pedagógico e do coordenador de cada departamento curricular, entre outros.

\footnotetext{
1 O conselho diretivo era constituído por três ou por cinco representantes do pessoal docente, conforme se tratasse de estabelecimentos, cuja frequência não excedesse mil alunos ou ultrapasse esse número, dois representantes dos alunos e um representante do pessoal não docente, sendo eleitos por corpos separados. Todos os professores e funcionários (pessoal técnico, administrativo e auxiliar) em serviço na respetiva escola poderiam eleger os seus representantes, no caso dos alunos (ensino complementar) seriam eleitos pelos delegados de turma. A presidência e vice-presidências eram assumidas por professores, desde que profissionalizados (DECRETO-LEI n 769 -A/76 de 23 de outubro).
} 
Neste quadro, a figura do presidente do conselho diretivo e, mais recentemente, do conselho executivo ${ }^{2}$, repartia a sua liderança não só com outros elementos do próprio órgão, mas com os demais órgãos de governação da escola na sua globalidade.

A partir do final da década de noventa assiste-se, na realidade portuguesa, à introdução de perspectivas gerencialistas no domínio da educação, nomeadamente na sua gestão. Do ponto de vista normativo-legal, não obstante as alterações ocorridas a partir do Decreto-Lei no 115-A/98, de 4 de maio, será o Decreto-Lei no 75/2008, de 22 de abril, que altera de modo mais significativo esse cenário de gestão menos democrática. Nesse panorama impõe-se um novo modelo de governação que prevê a existência de um órgão de gestão unipessoal e já não colegial, sendo a sua designação alterada, transitando-se de um conselho executivo e respetivo presidente para a figura do diretor ${ }^{3}$. Para além dessa mudança, atribui-se a esse órgão unipessoal um conjunto de novos poderes que até então eram repartidos com os demais órgãos de governação da escola, nomeadamente poderes relacionados com a escolha democrática destes mesmos órgãos. Note-se que, na legislação atual prevê-se que o procedimento de decisão dos detentores dos diferentes cargos na escola, por exemplo o de coordenador de departamento, consista na nomeação pelo diretor, ou seja, trata-se de uma concentração de poderes no órgão de gestão, em um único sujeito, no diretor de escola e "dessa forma alongando e verticalizando o respetivo organograma e reforçando as prerrogativas de uma liderança formalmente unipessoal” (LIMA, 2011, p.47). De modo específico,

[...] o director concentra sobre si vinte e cinco competências, preside ao conselho pedagógico por inerência, tudo parecendo girar em seu torno, fragilizando as estruturas colegiais existentes e pondo fim à quase totalidade dos processos de escolha democrática nas escolas [...]. O director passa, agora, a nomear e a demitir livremente o subdirector, os assessores, os coordenadores de departamentos, os coordenadores dos estabelecimentos agrupados, numa lógica gestionária de um perfil, um projeto, uma equipa de gestão, remetendo para algo semelhante ao princípio da 'unidade de comando', proposto no início do seculo XX por Henri Fayol (1984) (LIMA, 2011, p. 58).

\footnotetext{
2 O Decreto-Lei no 115-A/98, de 4 de maio, promove alterações no que se refere a este órgão, desde logo a possibilidade de ser um órgão colegial ou unipessoal, cabendo a decisão à escola. No caso da opção pela modalidade colegial, mantém a sua constituição por um presidente e dois vice-presidentes, estes têm de ser todos professores e deixam de fazer parte, deste órgão de gestão, os alunos e funcionários. No que se refere ao processo de eleição prevê-se uma assembleia eleitoral de base alargada, constituída pela totalidade do pessoal docente e não docente em serviço efetivo na escola, por representantes dos alunos (um por turma) e dos pais (no ensino básico, em número não superior ao número de turmas em funcionamento, no ensino secundários dois pais ou encarregados de educação, por cada ano de escolaridade) (cf. DECRETO-LEI no 115-A/98).

3 A figura do diretor é escolhida, após um processo misto entre concurso e eleição no seio do conselho geral dos agrupamentos de escolas/ escolas não agrupadas (cf. DECRETO-LEI, no 75/2008, artigos $18^{\circ}$ a $30^{\circ}$ ).
} 
A centralidade remetida ao diretor, responsável por cada escola não agrupada ou agrupamento de escolas pode ser um fator de erosão da gestão democrática e, consequentemente, de fragmentação das práticas de colegialidade dos profissionais e de escolha democrática. Neste sentido, foram criadas condições, do ponto de vista normativo-legal, para uma alteração profunda nas relações de poder no interior da escola, na medida em que se procura que "em cada escola exista um rosto, um primeiro responsável", no sentido de "reforçar a liderança da escola" e de conferir "maior eficácia", mas também mais "responsabilidade ao diretor" (DECRETO-LEI no 75/2008). No passado, nomeadamente no âmbito da gestão democrática, como já aqui fomos fazendo alusão, as relações de poder caracterizavam-se por tempos e espaços em que as decisões, ainda que apenas em matérias de gestão-execução, pautavam-se pela possibilidade de manifestação de interesses diversificados, pela liberdade de expressão e abertas à participação, por lógicas colegiais, especificamente no caso dos professores. Não obstante tais alterações, importa agora questionar a recepção desta nova figura de gestão nas escolas, de modo a problematizar se os diretores de escolas e os demais atores se conformam e reproduzem uma liderança unipessoal, uma liderança com maior poder, ou se, pelo contrário, resistem a tal imposição, de modo a desenvolverem práticas próximas da gestão democrática. Tais interrogações ganham maior interesse se tivermos em atenção que uma boa parte dos atuais diretores transitaram do órgão de gestão do modelo anterior para o atual, tal como é referido no estudo realizado por Lima, Sá e Rego (2017). Neste estudo, dos 156 diretores que responderam a um inquérito por questionário,

[...] 87 inquiridos dizem já terem exercido anteriormente o cargo de Presidente do Conselho Diretivo e 51 o cargo de Presidente do Conselho Diretivo (42 terão exercido anteriormente esses dois cargos), de onde se pode concluir que os diretores são recrutados de entre os professores com uma larga experiência profissional e que há uma significativa continuidade de professores que exerceram cargos equivalente em modelos de gestão anteriores, permitindo conceber a existência de uma 'carreira informal' de gestor escolar (LIMA et al., 2017, p. 220).

Face a este cenário, a presente investigação teve por objetivo conhecer e interpretar como tais responsáveis fizeram essa passagem. Assim, para uma compreensão no plano da ação desta nova realidade, realizámos um estudo de caso $^{4} \mathrm{e}$, a partir dos dados recolhidos nesse âmbito, selecionámos os relacionados com o perfil do diretor da escola, bem como com a liderança exercida nos anterior e atual modelos de gestão. A esse propósito será, ainda, de referir que para além da possibilidade de uma liderança mais democrática ou mais autoritária, outros tipos de lideranças ${ }^{4}$ O presente estudo insere-se em uma investigação mais ampla desenvolvida por um grupo de investigadores do Centro de Investigação em
Educação, Instituto de Educação, Universidade do Minho, sendo um dos seus eixos de análise a introdução da Nova Gestão Pública. 
emergem a partir da análise dos dados, o que nos permite apontar para a existência de uma liderança multifacetada, o que, por sua vez, nos remete para a complexidade no exercício do cargo de diretor.

\section{O estudo de um caso em uma investigação alargada: notas metodológicas}

A metodologia de suporte ao estudo situou-se em um paradigma de investigação naturalista, o método é o estudo de caso (YIN, 2005). Neste âmbito recorreu-se, de modo predominante, a duas técnicas de recolha da informação: o inquérito por entrevista a diferentes atores escolares, bem como à análise de documentos de cariz oficial (Regulamento Interno, Plano anual de Atividades, Projeto educativo, entre outros), como forma de se poder captar as orientações normativas produzidas no contexto escolar. As entrevistas definiram-se como semiestruturadas, intencionalmente realizadas. As questões foram sistematizadas em um guião comum e pré-concebido pela equipa mais alargada da investigação, sendo o mesmo utilizado com flexibilidade e adaptado ao perfil de cada escola/agrupamento e entrevistado. Segundo Amado e Ferreira (2014, p. 208-209) neste tipo de entrevista "As questões derivam de um plano prévio, um guião onde se define e regista, numa ordem lógica para o entrevistador, o essencial do que se pretende obter, embora, na interação se venha a dar uma grande liberdade de resposta ao entrevistado". Deste modo, não há "uma imposição rígida de questões, o que permite que ao entrevistado discorrer sobre o tema proposto, 'respeitando os seus quadros de referência', salientando o que para ele for mais relevante, com as palavras e a ordem que mais lhe convier e, possibilitando, a captação imediata e corrente das informações desejadas".

Assim, obteve-se um número total de doze entrevistados, a saber: representante da autarquia do conselho geral, representante dos funcionários no conselho geral, presidente do conselho geral, representante dos professores no conselho geral, professor mais novo da escola, professor mais velho da escola, dois coordenadores de departamento, ex-presidente da associação de estudantes ${ }^{5}$, presidente da associação de pais e encarregados de educação e expresidente dessa associação ${ }^{6}$ e diretor de escola. A realização das entrevistas ocorreu no final do ano letivo de 2014/2015 e todas as entrevistas foram efetuadas nas instalações da escola, nomeadamente em gabinetes pertencentes à direção. As referidas entrevistas, cuja duração média se situou entre quarenta minutos e duas horas ${ }^{7}$, foram registadas

5 Optámos por realizar a entrevista ao ex-presidente da associação de estudantes uma vez que a escola nesta fase se encontrava em diligências para promover as eleições e, consequentemente, a referida associação estava inativa e sem presidência.

6 A entrevista ao ex-presidente da associação de pais justificou-se na medida em que o atual presidente havia tomado posse há muito pouco tempo e este sugeriu que fosse entrevistado o anterior, dada a sua vasta experiência no cargo em causa.

7 Agradecemos ao diretor da escola que, para além de garantir excelentes condições para a realização das entrevistas, sempre se disponibilizou para colaborar nesta investigação. Agradecemos igualmente aos demais atores que cederam o seu tempo para colaborar com este estudo. 
sob a forma de áudio, após a obtenção das autorizações dos respetivos entrevistados. Os participantes ficaram cientes de que os dados obtidos poderiam ser divulgados junto da comunidade académica, respeitando o carácter confidencial das identidades. O procedimento de tratamento dos dados recaiu na análise de conteúdo, a partir das categorias de análise definidas a priori $^{8}$. Para uma melhor caracterização socioprofissional dos entrevistados, no Quadro 1 faz-se referência aos seguintes dados: sexo, idade, área disciplinar, tempo na escola e qualidade em que é entrevistado.

\section{Quadro 1. Caracterização socioprofissional dos entrevistados}

\begin{tabular}{|c|c|c|c|c|}
\hline Entrevistado na qualidade de & Sexo & Idade & Área Disciplinar & Tempo na escola \\
\hline Representante da Autarquia & Masculino & 58 & - & $\begin{array}{l}\text { Representante na Assembleia de } \\
\text { Escola }\end{array}$ \\
\hline $\begin{array}{l}\text { Ex- Presidente da Associação de } \\
\text { Pais e Encarregados de Educação }\end{array}$ & Masculino & 48 & - & - \\
\hline $\begin{array}{l}\text { Presidente da Associação de Pais } \\
\text { e Encarregados de Educação }\end{array}$ & Masculino & 42 & - & $\begin{array}{l}1^{\circ} \text { ano de mandato } \\
\text { Educanda } 8^{\circ} \text { ano }\end{array}$ \\
\hline $\begin{array}{l}\text { Representante dos Professores no } \\
\text { Conselho Geral }\end{array}$ & Masculino & 57 & Humanidades & 25 anos \\
\hline $\begin{array}{l}\text { Representante dos Funcionários } \\
\text { no Conselho Geral }\end{array}$ & Masculino & 47 & - & 18 anos \\
\hline Professora mais velha & Feminino & 60 & Matemática & 7 anos \\
\hline Professora mais novo & Masculino & 48 & Engenheiro Mecânico & 7 anos \\
\hline Coordenadora do Departamento & Feminino & 50 & Humanidades & 23 anos \\
\hline Coordenador do Departamento & Masculino & 57 & Geologia & 23 anos \\
\hline $\begin{array}{l}\text { Ex-Presidente da Associação de } \\
\text { Estudantes }\end{array}$ & Masculino & 21 & - & - \\
\hline Presidente do Conselho Geral & Masculino & 52 & Informática & $\begin{array}{l}25 \text { anos } \\
\text { Presidente da Assembleia de Escola }\end{array}$ \\
\hline Diretor & Masculino & 59 & $\begin{array}{l}\text { Engenharia de Sistemas Informáticos } \\
\text { Especialização em Administração Escolar }\end{array}$ & $\begin{array}{l}32 \text { anos } \\
1985 \text { - inicia funções na gestão }\end{array}$ \\
\hline
\end{tabular}

Fonte: Elaborado pelas autoras.

8 Algumas limitações foram encontradas no presente estudo, sendo de destacar as seguintes e possíveis recomendações: i) a análise incidiu sobre os discursos dos atores educativos, recomendamos que no futuro se considere a confrontação destes com a ação organizacional, através da observação de diferentes contextos e reações dos atores educativos pertencentes às estruturas de poder da escola e ii) a análise incidiu sobre os atores educativos pertencentes na sua grande maioria às estruturas de poder da escola, revelando-se fundamental incluir outros atores educativos, nomeadamente professores, que não são membros dos órgãos de gestão. 
A entrevista semidiretiva ganha um lugar central nesta investigação e, nesse sentido, importa clarificar que o procedimento da análise de conteúdo lato sensu toma por base os discursos de diferentes atores desta escola, que quotidianamente trabalham com o diretor de escola, bem como os discursos do próprio diretor. Nos pontos que se seguem apresentamos tais dados, bem como a sua problematização em torno da liderança multifacetada do diretor de escola.

\section{Perfil do Diretor}

O diretor da escola em causa ${ }^{9}$ é do sexo masculino e tem 59 anos de idade. É professor do quadro, nessa escola, desde 1982, e exerce funções de gestão escolar desde 1985. Assim, é possuidor de uma vasta experiência nesse domínio, de mais de 25 anos. Logo na sua primeira candidatura, em 1985, ocupa o cargo de responsável máximo, na altura, designado de Presidente do Conselho Diretivo, exercendo, mais tarde, também o de Presidente do Conselho Executivo e, atualmente, o de Diretor. Ao longo destes anos, apesar dos diferentes modelos de gestão pelos quais passou, regista-se uma significativa continuidade no seu exercício, uma vez que esse diretor assumiu, anteriormente, cargos equivalentes ao atual.

Note-se que, no caso deste diretor, o primeiro contacto com a gestão foi logo como presidente, o que indicia que a experiência prévia e/ou a formação especializada não foram condições para o seu exercício. A sua entrada para o mundo da gestão escolar é consequência da "força das circunstâncias", designadamente da "pressão dos pares", sendo que estes lhe reconheceram, e reconhecem, capacidades para a gestão e o "empurraram" para tal. Nas suas palavras:

"Fui empurrado. É o habitual. Nós intervimos, quando somos voluntariosos, somos notados; sugerimos, propomos e somos notados, E, de repente, estamos a ser empurrados. Eu acedi integrar a gestão, na altura, porque já estava saturado de tanta pressão. Lembro-me que na escola dizia que não, não. [...]. Estava a sair de casa para ir à mercearia [...] e apareceu um colega a falar nisso e eu disse: 'ponham lá o meu nome, e não me chateiem mais' [...]. Por azar meu, foi a lista em que eu estava que ganhou as eleições e, por maldade, puseram o meu nome à frente. E, quando, digamos, tomei consciência, estava toda a gente a olhar para mim, eu seria o Presidente do Conselho Diretivo. Meti-me no barco, há que navegar! A partir daí foi muito problemático, sem qualquer experiência, sem nada. O primeiro mandato foi muito difícil. [...]. Eu

\footnotetext{
9 Os critérios de seleção desta escola foram plurais: o facto de a escola não estar integrada em nenhum agrupamento de escolas (sobre agrupamento de escola, ver LIMA; 2004), ter anteriormente participado em investigações desenvolvidas por alguns membros desta equipa e, ainda, a disponibilidade para colaborar na investigação.
} 
tinha na altura 29 anos, acho eu, e tive de instaurar processos disciplinares a pessoas com 59 anos, quase 60. Foi difícil. De lá para cá, tem sido sempre a mesma luta, se tenho algum problema, tenho de resolvê-lo, posso não conseguir hoje, talvez daqui a um mês, dois meses, um ano [...]. Eu estou aqui porque gosto de realizar projetos." (Informação verbal)

Não obstante as dificuldades iniciais, esse responsável manteve-se por mais de 30 anos no órgão de gestão. A partir dos discursos dos atores e do próprio diretor, sobressai ao longo desse período uma liderança multifacetada ${ }^{10}$ e, no seu seio, uma faceta democrática, assunto a que nos dedicamos no próximo ponto.

\section{Liderança multifacetada e em contracorrente à erosão da gestão democrática}

A identificação de uma liderança multifacetada no exercício do cargo por parte deste diretor em estudo leva-nos a romper com a ideia de que os diretores exercem apenas um tipo de liderança, independentemente dos grupos de atores com quem interagem, dos contextos, das situações imprevistas e de incertezas que venham a surgir no quotidiano de uma escola. Deste modo, consideramos que o tipo de liderança exercido por diretores de agrupamentos de escolas/ escolas não agrupadas pode assumir um carácter contingente, exigindo uma análise a partir de uma referenciação concetual plural e que serviu de apoio para a identificação de uma liderança multifacetada na presente investigação. Neste contexto podemos sinalizar algumas dimensões próximas das lideranças "tipos ideais" e que coexistem na ação do diretor em análise. No presente exercício selecionamos aqueles tipos de liderança que nos foram apontadas com maior regularidade nos discursos dos atores entrevistados, bem como do próprio diretor, a saber: a liderança empresarial/gerencialista, a liderança antagonista/reivindicativa e a liderança democrática.

Nos discursos dos atores encontramos traços de uma liderança de tipo empresarial e gerencialista, mas antes desta identificação importa esclarecer a definição de gerencialismo apresentada por Newman e Clarke (2012, p. 359), nas suas palavras:

O gerencialismo é uma ideologia que legitimava direitos ao poder, especialmente ao direito de gerir, construídos como necessários para alcançar maior eficiência na busca de objetivos organizacionais e sociais (ver também Pollitt, 1993, capítulo 1). Em segundo lugar, o gerencialismo é uma estrutura calculista que organiza o conhecimento sobre as metas organizacionais e os meios para alcançá-las. Usualmente

\footnotetext{
${ }^{10}$ Para a apresentação destes tipos de ação inspiramo-nos em modelos de análise organizacional e em algumas tipologias sobre liderança na escola.
} 
está estruturado em torno de um cálculo interno de eficiência (entradas-saídas) e um cálculo externo de posicionamento competitivo em um campo de relações de mercado. Contudo, o gerencialismo também é uma série de discursos superpostos que articulam proposições diferentes - até mesmo conflitantes - a respeito de como gerir e do quê deve ser gerido.

Assim, nesse cenário, a preocupação destes gestores seria o controle prático dos custos por uma maior eficiência. No que ao papel do responsável organizacional diz respeito, quanto à nova configuração gerencial, esclarecem os autores:

Os gerentes representavam uma contrapartida ao profissionalismo de gabinete porque se imaginava que habitassem o mundo da ação de mercado e eram os carreadores naturais de seu empreendedorismo e dinamismo. Podiam oferecer toda a gama de boas práticas em negócios que as organizações no setor público precisavam aprender (NEWMAN; CLARKE, 2012, p. 359).

No caso da escola em estudo, como já referimos, apenas encontramos alguns traços dessa lógica, trata-se de uma ação orientada para a gestão dos recursos da organização, sobretudo para a necessidade de a escola gerar receitas próprias, tornando-se desse modo mais autónoma. Como depreendemos das palavras do próprio diretor:

"Percebi que a escola para fazer qualquer coisinha tinha que andar a pedir, [...]; se queríamos um retroprojetor tínhamos que ir pedir, se queríamos qualquer coisa, 'andávamos sempre de mão estendida'. [...]. Entendi que tínhamos de arranjar uma via alternativa. Então, comecei a pensar em fontes de receita para a escola, surgiu a ideia de fazer o equipamento desportivo, estaríamos em 1991 ou 1992,... evidente que não tínhamos dinheiro para se fazer o equipamento desportivo, aquilo era para se ir fazendo. Ao fim de seis anos o equipamento estava pronto, portanto, neste momento é uma fonte de receitas para a escola [...]. Para os nossos projetos, diria que somos quase autossuficientes, [...] que nos permite fazer muitas coisas, dá-nos alguma autonomia efetiva, porque falar de autonomia de escola, sem capacidade financeira não é autonomia. [...]. Temos um problema, temos de resolver, qualquer escola tem de tentar criar fontes de receita." (Diretor da escola)

A importância de alguma autonomia financeira também é reforçada por outros atores, que reconhecem que esta é uma conquista do diretor da escola: 
“[...] se não há financiamento para tal, portanto, não há autonomia, a autonomia está como lhe disse inteiramente ligada ao orçamento aquilo que a escola dispõe. [...] este é o grande problema, não só das escolas, é um grande problema de todos os setores que são dependentes financeiramente do Estado. [...] esta escola trabalha e trabalhou muito ao longo destes anos todos sem dependência do Estado." (Representante da autarquia no Conselho Geral, informação verbal)

Assim, parece ser justamente esta capacidade de gerar receitas próprias que define um bom líder, como reforça o discurso desse outro ator: se existir um bom gestor, a escola tem sempre mais valia [...], um bom gestor para conseguir captar verbas ou recursos para a escola é sempre uma mais valia" (representante dos funcionários no conselho geral).

Tal situação ganha maior inteligibilidade se atendermos ao carácter centralizado da administração educativa (FORMOSINHO, 1986; LIMA, 1998), que parece assumir uma lógica burocrática. Nessa perspetiva, as escolas são detentoras de parcas áreas de autonomia, nomeadamente no que a gestão de verbas diz respeito. Acresce a este facto, o orçamento concedido às escolas, tido como insuficiente.

Seja como for, o que é facto é que essa situação apresenta contornos de uma liderança de tipo empresarial, sendo ainda mais promovida com a introdução de políticas, no domínio da educação pública, de caracter gerencialista. Nesse contexto, a captação de verbas por parte das instituições públicas parece começar a ser uma realidade e um parâmetro de classificação de boas práticas das organizações. Contudo, é importante ressaltar que na perspetiva do diretor e dos demais entrevistados, tais receitas são investidas na própria escola, o que revela a complexidade dessa questão.

Em síntese parcial, registam-se discursos que associam um bom líder à capacidade de gerar receitas próprias, que acabam por reverter para a comunidade escolar, e, inclusive, para a comunidade mais alargada. Neste contexto, parece existir um denominador comum, o estabelecimento de uma relação entre possuir receitas próprias e existir autonomia de escola. Por outras palavras, transparece das falas dos atores que gerar receitas próprias é um indicador de autonomia que, simultaneamente, permite o seu exercício noutros domínios, designadamente no que se refere ao domínio pedagógico.

A par desse posicionamento alia-se a liderança de tipo antagonista/reivindicativa (BALL, 1994) no exercício do cargo de diretor. No sentido atribuído pelo autor, esta pauta-se pela confrontação e discussão, como forma de manter o controle sobre a organização. No caso específico da ação do diretor em estudo, esse tipo de liderança revela-se na sua posição de reivindicação junto do Ministério da Educação, como podemos constatar nos excertos que apresentamos:

“[...] não é uma escola submissa [...] a escola é uma escola ativa até, de confrontar o ministério, o ministério tem uma postura que de facto é de lamentar.” (Ex-presidente da Associação de Pais). 
“[...] nós temos a sorte, mais uma vez, primeiro o diretor, mas também a direção, que tem bastante abertura para aceitar que não seja de ânimo leve que se cumpra qualquer diretiva, que são ordens do ministério da educação, e quando são ordens que remédio temos nós, embora nós contestemos algumas diretivas." (Professora mais velha)

Talvez seja, por isso mesmo, por existir esta postura de confronto e de contestação, que o antigo presidente da associação de estudantes caracteriza a relação entre a escola e o ministério como sendo "uma relação tensa".

Finalmente, um outro tipo de liderança exercido por este diretor aproxima-se da liderança democrática. Esta assume especial relevância se atendermos ao contexto normativo-legal que prevê um órgão unipessoal, que concentra e chama para si poderes, que até então eram da competência de diferentes órgãos colegiais da escola. Assim, da análise dos discursos recolhidos, constatamos que os atores entrevistados claramente identificam, do ponto de vista normativo-legal, a concentração de poderes na figura do diretor de escola, como podemos confirmar nos seguintes extratos:

"Na lei, onde se decide é ali mesmo no gabinete do diretor.” (Professora mais antiga)

"Se lermos a legislação de uma forma muito restritiva nem tudo pode ser delegado, o que é que vai acontecer vamos concentrar tudo no diretor, criando uma situação terrível." (Coordenador de departamento)

No entanto, no domínio da ação organizacional da escola investigada os atores negam uma liderança menos democrática por parte do diretor de escola, como podemos verificar nas palavras que se seguem:

“[...] ele não pede a opinião para dizer eu estou acompanhado ou sozinho, ele pede genuinamente, é alguém com espírito democrático, felizmente, ainda bastante dentro da cabeça.” (Professora mais velha da escola)

“[...] quando a legislação manda o diretor indicar, nomear cargos, são todos de nomeação que é uma coisa que me incomoda profundamente, o nosso diretor já com muitas restrições dá oportunidade aos grupos, a que cada um deles individualmente possam eleger dentro das condicionantes quem os vai representar." (Professora mais velha na escola)

“Aqui sempre foi privilegiada a via democrática, sempre dei aos departamentos a possibilidade de elegerem o coordenador, é um dos princípios, a democracia [...]. Nesse aspeto, a postura foi sempre a mesma." (Diretor da escola) 
A passagem serena da gestão colegial para a unipessoal teve como principal razão a continuidade da pessoa que ocupa o cargo de gestão e as tentativas de manutenção do estilo de liderança adquirido no passado:

"Não mudou muito, são as mesmas pessoas, não se muda a mentalidade porque a lei mudou." (Presidente do Conselho Geral)

"Como nós temos vindo a atravessar a gestão com a mesma pessoa; ou seja, com o diretor não notamos muito essa diferença." (Professor do Conselho Geral)

"Não sentimos grandes mudanças porque o sr. diretor ou antigo presidente do conselho executivo sempre teve aquelas linhas orientadoras e, portanto, não fugiu muito do que era e do que é." (Funcionário do Conselho Geral)

“[onde reside o maior poder na escola] - É na direção, no diretor, neste caso. É consequência do modelo que impuseram, mas a minha prática continua a ser a mesma. Embora tenha poder, não vou utilizar, só por utilizar." (Diretor da escola)

Portanto, há uma mudança normativa-legal na relação de poderes no interior na escola. Contudo, na escola em causa, sendo o diretor a mesma pessoa que ocupou cargos diretivos no passado, a figura de presidente do órgão de gestão e que procura segundo os discursos dos atores manter o estilo de liderança desenvolvido no âmbito da gestão democrática, parece estarmos face a uma mudança na continuidade. Se com a implementação desse novo modelo de gestão se pretendia a substituição da gestão democrática por uma gestão de feição mais vertical/hierárquica, as margens de ação dos atores, nomeadamente as do diretor, acabam por não permitir a sua implementação na plenitude.

\section{Considerações finais}

Da investigação realizada em torno da figura do diretor de escola constatamos que do ponto de vista legislativo as alterações, em termos de gestão da escola pública, prendem-se com a existência de um órgão de gestão unipessoal, que concentra em si novas competências, sendo que no passado para além de se tratar de um órgão colegial repartia algumas destas competências com as demais estruturas de governo da escola. Porém, com a realização de um estudo de caso, tivemos oportunidade de verificar que, no plano da ação, não ocorreu a reprodução plena deste modelo, o que terá contribuído para uma passagem serena para essa nova realidade. Neste sentido, vários atores entrevistados, incluindo o diretor, qualificaram a sua liderança como semelhante à de um líder democrático, que 
valoriza a opinião e a decisão coletiva. Assim, os discursos apontam para um certo afastamento do que está previsto na legislação. A contribuir para essa situação encontra-se o facto de o cargo ser ocupado pela mesma pessoa que já tinha ocupado lugar semelhante no modelo anterior, o que lhe permitiu ao longo de mais de 30 anos adquirir uma outra experiência e prática em termos de gestão, caracterizada por ser mais democrática, como já aludimos Tal situação parece ter permitido adiar uma erosão mais acentuada desse modelo de gestão democrática, criando um obstáculo à implementação linear de uma lógica gerencialista neste domínio. Este quadro possibilita-nos colocar como hipótese tratar-se de uma especificidade portuguesa, realidade distinta da de outros países. Desse modo, medidas semelhantes implementadas em Portugal e noutros países, de carácter gerencialista, podem conduzir a processos, efeitos e resultados distintos.

Para além desta faceta de liderança do diretor da escola em causa, predomina um estilo de atuação bastante proactivo e empreendedor, nomeadamente no que se refere ao fazer face à necessidade de a escola gerar receitas próprias, o que nos leva a uma aproximação de uma liderança de tipo empresarial e gerencial, mas também de uma liderança antagonista/reivindicativa, na medida em que esse diretor procura junto do Ministério da Educação ter voz em determinadas decisões que afetam a escola.

É neste contexto que são reveladas algumas dimensões dos diferentes tipos de liderança, que constituem uma liderança multifacetada, rompendo com um certo mito de um tipo único de liderança exercido pelo diretor de escola, independentemente dos grupos de atores com quem este interage, das situações imprevistas e de incertezas que venham a surgir no quotidiano de uma escola. Deste modo, consideramos que o tipo de liderança, exercido por diretores de agrupamentos de escolas/escolas não agrupadas, pode assumir um carácter contingente, exigindo uma análise complexa, e não simplista, do seu exercício.

\section{Agradecimentos}

Este trabalho foi financiado pelo CIEd - Centro de Investigação em Educação, projetos UID/CED/1661/2013 e UID/CED/1661/2016, Instituto de Educação, Universidade do Minho, através de fundos nacionais da FCT/ MCTES-PT.

\section{Referências}

AMADO, João; FERREIRA, Sónia. A entrevista na investigação educacional. In: AMADO, João (coord.). Manual de Investigação Qualitativa em Educação. Coimbra: Imprensa da Universidade de Coimbra, 2014. p. 207-232. https://doi.org/ 10.14195/978-989-26-0879-2 
BALL, Stephen. La Micropolítica de la Escuela. Hacia una Teoría de la Organización Escolar. Barcelona: Ediciónes Paidos, 1994.

BRASIL. Decreto-lei no 769-A, de 23 de outubro de 1976. Gestão Democrática dos Estabelecimentos de Ensino Preparatório e Secundário. Brasília, DF: Presidência da República, 1976.

BRASIL. Decreto-lei no 75, de 22 de abril de 2008. Regime de Autonomia, Administração e Gestão dos Estabelecimentos Públicos da Educação Pré-Escolar e dos Ensinos Básico e Secundário. Brasília, DF: Presidência da República, 2008. https://doi. org/10.11606/d.2.2010.tde-27092011-090553

BRASIL. Decreto-lei no 115-A, de 4 de maio de 1998. Regime de Autonomia, Administração e Gestão de Estabelecimentos da Educação Pré-Escolar. Brasília, DF: Presidência da República, 1998.

CLARKE, Janet; NEWMAN, John. Gerencialismo. Educ. Real., v. 37, n. 2, p. 353-381, 2012.

FORMOSINHO, João. A regionalização do sistema de ensino. Cadernos Municipais: Revista de Ação Regional e Local, [s. l.], n. 3839, p. 63-67, dez. 1986.

LIMA, Licínio. A administração do sistema educativo e das escolas (1986/1996), Ministério da Educação. A Evolução do Sistema Educativo e o PRODEP. Lisboa: Ministério da Educação/Comunidade Europeia, 1998. p. 17-96. https://doi.org/10.14201/ gredos. 129772

LIMA, Licínio. O agrupamento de escolas como o novo escalão da administração desconcentrada. Revista Portuguesa de Educação, [s. l.], v. 17, n. 2, p. 7-47, 2004.

LIMA, Licínio. Diretor de escola: subordinação e poder. In: NETO-MENDES, António; COSTA, Jorge A.; VENTURA, Alexandre (org.). A Emergência do Director da Escola, Questões Políticas e Organizacionais. Atas do VI Simpósio sobre organização e gestão escolar. Aveiro: Universidade de Aveiro, 2011. p.47-63,. https://doi.org/10.5935/972-789-145-4.2016c047

LIMA, Licínio. A gestão democrática das escolas: do autogoverno à ascensão de uma pós-democracia gestionária. Educ. Soc, [s. l.], v. 35, n. 129, p. 1067-1083, 2014. https://doi.org/10.1590/es0101-73302014142170

LIMA, Licínio; SÁ, Virgínio; REGO, Guilherme. O que é a democracia na 'gestão democrática das escolas'? In: LIMA, Licínio; SÁ, Virgínio, O governo das Escolas. Vila Nova de Famalicão: Húmus/Universidade do Minho. p. 213-258, 2017. https://doi. org/10.22409/mov.v5i8.444

YIN, Robert. Estudo de Caso: Planejamento e Métodos. Porto Alegre: Bookman, 2005. 
Recebido em: 12/8/2018.

Aprovado em: 27/2/2019.

Publicado em: 31/12/2019.

\section{Endereço para correspondência:}

Fernanda Santos Martins

Universidade do Minho (UMINHO)

Largo do Paço

4704-553, Braga, Portugal

\section{Autoras:}

Fernanda Santos Martins

Docente do Departamento Ciências Sociais da Educação. Investigadora do Centro de Investigação em Educação, Instituto de Educação da

Universidade do Minho, Portugal.

Orcid: https://orcid.org/0000-0003-2008-5921

E-mail: fmartins@ie.uminho.pt

Ana Paula Macedo

Investigador da UICISA - Escola Superior de Enfermagem de Coimbra. Docente na Escola Superior de Enfermagem, Centro de Investigação em Educação, Universidade do Minho.

Orcid: https://orcid.org/0000-0002-1064-3523

E-mail: amacedo@ese.uminho.pt 